\title{
Most Diseases Originate from Defects in Bone Marrow: A New Therapy for Replacing Abnormal Hemopoietic Stem Cells (HSCs) and Mesenchymal Stem Cells (MSCs) with Normal Ones
}

\section{Susumu Ikehara*}

Department of Stem Cell Disorders, Kansai Medical University, Japan

\section{Introduction}

Bone Marrow Transplantation (BMT) is becoming a powerful strategy for the treatment of hematologic disorders (leukemia, aplastic anemia, etc.), congenital immunodeficiencies, metabolic disorders [1], and also autoimmune diseases [2]. In the case of autoimmune diseases, we have found using various animal models that BMT can be used to treat diseases such as Systemic Lupus Erythematosus (SLE), Rheumatoid Arthritis (RA), Immune Thrombocytopenic Purpura (ITP), InsulinDependent Diabetes Mellitus (IDDM), chronic glomerulonephritis, and also a certain type of Non-Insulin-Dependent Diabetes Mellitus (NIDDM) [2,3]. In addition, we have found that autoimmune diseases are stem cell disorders: BMT from autoimmune-prone mice to normal mice can induce autoimmune diseases in the normal mice [4,5]. However, in MRL/lpr mice, which are radiosensitive ( $<8.5 \mathrm{~Gy})$, we found that conventional intravenous BMT (IV-BMT) had a transient effect on autoimmune diseases, which were found to recur [6]. We therefore focused on how we might prevent and treat autoimmune diseases in radiosensitive and chimeric-resistant MRL/lpr mice.

We found that stromal cells play a crucial role in preventing graft failure [7-9], since there is a Major Histocompatibility Complex (MHC) restriction between Hemopoietic Stem Cells (HSCs) and stromal cells [10]. To prevent the recurrence of autoimmune diseases in MRL/lpr mice, we found that "Intra-Bone Marrow (IBM)-BMT" (intra-bone marrow injection of whole BMCs into the bone marrow cavity) is the best strategy for allogeneic BMT [11].

To apply allogenic BMT to humans, we extensively carried out BMT to clarify which cells were essential for successful BMT and finally found that MSCs play a crucial role in preventing graft failure, since there is a major histocompatibility complex restriction between HSCs and MSCs. These early observations gave way to studies on improved methods of not only isolating stromal cells, including Mesenchymal Stem Cells (MSCs), but also characterizing the ideal conditions for successful allogeneic BMT $[7,10]$.

In this review article, we show that our new method can be used to treat various intractable diseases, such as autoimmune diseases and age-associated diseases (osteoporosis and emphysema, etc.).

\section{References}

1. Thomas ED (2000) Landmarks in the development of hematopoietic cell transplantation. World J Surg 24: 815-818.

2. Ikehara S (2001) Treatment of autoimmune diseases by hematopoietic stem cell transplantation. Exp Hematol 29: 661-669.

3. Ikehara S (2003) A novel strategy for allogeneic stem cell transplantation: perfusion method plus intra-bone marrow injection of stem cells. Exp Hemato 31: $1142-1146$

4. Ikehara S, Kawamura M, Takao F, Inaba M, Yasumizu R, et al. (1990) Organ-specific and systemic autoimmune diseases originate from defects in hematopoietic stem cells. Proc Natl Acad Sci USA 87: 8341-8344.

5. Kawamura M, Hisha H, Li Y, Fukuhara S, Ikehara S (1997) Distinct qualitative differences between normal and abnormal hemopoietic stem cells in vivo and in vitro. Stem Cells 15: 56-62.

6. Ikehara S, Yasumizu R, Inaba M, Izui S, Hayakawa K, et al. (1989) Long-term observations of autoimmune-prone mice treated for autoimmune disease by allogeneic bone marrow transplantation. Proc Natl Acad Sci USA 86: 3306 3310 .

7. Ishida T, Inaba M, Hisha H, Sugiura K, Adachi Y, et al. (1994) Requirement of donor-derived stromal cells in the bone marrow for successful allogeneic bone marrow transplantation: complete prevention of recurrence of autoimmune diseases in MRL/Mp-lpr/lpr mice by transplantation of bone marrow plus bone (stromal cells) form the same donor. J Immunol 152: 3119-3127.

8. Kushida T, Inaba M, Hisha H, Ichioka N, Esumi T, et al. (2001) Crucial role of donor-derived stromal cells in successful treatment for intractable autoimmune diseases in MRL/Ipr mice by BMT via portal vein. Stem Cells 19: 226-235.

9. Fan TX, Hisha H, Jin TN, Yu CZ, Lian ZX, et al. (2001) Successful allogeneic bone marrow transplantation (BMT) by injection of bone marrow cells via portal vein: Stromal cells as BMT-facilitating cells. Stem Cells 19: 144-150.

10. Hashimoto F, Sugiura K, Inoue K, Ikehara S (1997) Major histocompatibility complex restriction between hematopoietic stem cells and stromal cells in vivo. Blood 89: 49-54

11. Kushida T, Inaba M, Hisha H, Ichioka N, Esumi T, et al. (2001) Intra-bone marrow injection of allogeneic bone marrow cells: A powerful new strategy for treatment of intractable autoimmune diseases in MRL/lpr mice. Blood 97: 3292 3299 .
*Corresponding author: Susumu Ikehara, MD, PhD, Department of Stem Disorders, Kansai Medical University, Japan, E-mail: ikehara@takii.kmu.ac.jp

Received November 22, 2012; Accepted November 23, 2012; Published November 24, 2012

Citation: Ikehara S (2012) Most Diseases Originate from Defects in Bone Marrow. A New Therapy for Replacing Abnormal Hemopoietic Stem Cells (HSCs) and Mesenchymal Stem Cells (MSCs) with Normal Ones. J Blood Lymph 2:e110. doi:10.4172/2165-7831.1000e110

Copyright: (c) 2012 Ikehara S. This is an open-access article distributed unde the terms of the Creative Commons Attribution License, which permits unrestricted use, distribution, and reproduction in any medium, provided the original author and source are credited. 